predicted; $53.5 \pm 19.9$ vs $46.4 \pm 18.9, \mathrm{p}<0.001$. Following adjustment for $\mathrm{FEV}_{1} \%$ predicted, there were no gender differences in SGRQ $(51.2 \pm 18.6$ vs $49.8 \pm 19.5, \mathrm{p}=0.127)$ or MRC dyspnoea scores (3.0 $(2.0,4.0)$ vs $3.0(2.0,4.0), \mathrm{p}=0.104)$. Cardiovascular conditions were more common in male COPD patients (Abstract P46 figure 1), whereas of the clinically significant comorbidities, only osteoporosis was more common in females $(10.4 \%$ vs $2.7 \%, \mathrm{p}=0.001)$.

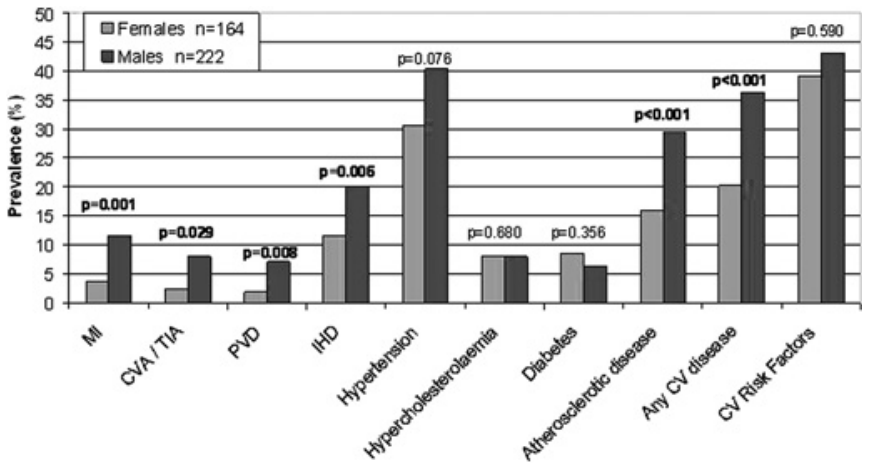

Abstract P46 Figure 1 Gender differences in the prevalence of cardiovascular diseases in COPD. MI, myocardial infarction, CVA, cerebrovascular accident, TIA, transient ischaemic attack; PVD, peripheral vascular disease; IHD, ischaemic heart disease, CV, cardiovascular.

Conclusions The excess cardiovascular disease in COPD patients is predominantly found in men despite lower gender differences in cardiovascular risk factors such as smoking history, diabetes, hypercholesterolaemia and hypertension. This may partly represent under-diagnosis of cardiovascular disease in COPD patients. Clinical vigilance must be maintained to identify and optimally manage important comorbidities in all COPD patients, although clinicians should be aware of the increased prevalence of cardiovascular disease in men and osteoporosis in women.

\section{P47 THE IMPACT OF COMORBID ISCHAEMIC HEART DISEASE ON EXERCISE CAPACITY IN COPD PATIENTS}

\author{
doi:10.1136/thoraxjnl-2011-201054c.47
}

A R C Patel, A D Alahmari, G C Donaldson, B Kowlessar, A J Mackay, R Singh, J R Hurst, J A Wedzicha. Academic Unit of Respiratory Medicine, UCL Medical School, London, UK

Introduction Comorbid ischaemic heart disease (IHD) is associated with an adverse impact on health status, symptoms (ARJCCM 2011;183:A2614) and exacerbation recovery in COPD patients (ERJ 2010;954s:E5209). Any impact on exercise capacity is poorly understood. We aimed to assess and quantify differences in exercise capacity in stable COPD patients with and without IHD.

Methods We assessed 6-min walking distance (6MWD) in accordance with ATS guidance (AJRCCM 2002;166:111-117) in patients from the London COPD cohort. All assessments were performed in the stable state with no symptom-defined exacerbations recorded on daily diary cards for 6 weeks prior and 2 weeks following the visit. Dyspnoea and fatigue were measured before and after the test using the Borg scale, as were saturations from a pulse oximeter. Data were analysed using unpaired t-tests, Mann-Whitney $U, \chi^{2}$ tests and multiple regression techniques.

Results 115 patients had a 6MWD assessment, 19 (17\%) had IHD (Abstract P47 table 1). COPD patients with IHD had a lower mean \pm SD $6 \mathrm{MWD}$ than those without $(310 \pm 138$ vs $354 \pm 107 \mathrm{~m})$ although this was not statistically significant $(p=0.119)$. Following adjustment for age, gender, $\mathrm{FEV}_{1} \%$ predicted, BMI and smoking pack year history, IHD was found to be independently related with a $66 \mathrm{~m}$ reduction in $6 \mathrm{MWD}(95 \%$ CI 5 to $127 \mathrm{~m}), \mathrm{p}=0.035$. Median (IOR) dyspnoea on the Borg scale before the test was not higher in those with IHD $(1(1,2)$ vs $1(0,3), p=0.135)$, this increased more in those with IHD compared to those without during the test $(2(1,3)$ vs $1(0,3), p=0.043)$. Fatigue measured on the Borg scale was higher at the start of the test in those with $\operatorname{IHD}(1.5(0,3)$ vs $0(0,2)$, $\mathrm{p}=0.038$ ), however, the increase after the test was not different between the groups $(0(0,2)$ vs $0(0,2), \mathrm{p}=0.831)$. The mean $\pm \mathrm{SD}$ pretest oxygen saturations and post-test change were similar in those with and without IHD $(93.8 \pm 2.6 \%$ vs $94.1 \pm 2.4 \%, p=0.684$ $-0.9 \pm 4.4 \%$ vs $-1.4 \pm 3.2 \%, p=0.595)$.

Abstract P47 Table 1 Clinical characteristics of COPD patients with and without comorbid ischaemic heart disease (IHD)

\begin{tabular}{|c|c|c|c|c|}
\hline & $\begin{array}{l}\text { All COPD } \\
\text { patients } \\
(\mathrm{n}=115)\end{array}$ & $\begin{array}{l}\text { COPD without } \\
\text { IHD } \dagger(n=96)\end{array}$ & $\begin{array}{l}\text { COPD with } \\
\text { IHD } \neq(n=19)\end{array}$ & $\begin{array}{l}\text { p Value } \\
\dagger \text { vs } \neq\end{array}$ \\
\hline Age (years) & $69.7 \pm 8.7$ & $68.9 \pm 8.9$ & $74.0 \pm 5.9$ & 0.019 \\
\hline Male gender & $67 \%$ & $65 \%$ & $79 \%$ & 0.224 \\
\hline $\mathrm{FEV}_{1}$ (\% predicted) & $51.9 \pm 18.6$ & $52.3 \pm 19.2$ & $49.5 \pm 15.5$ & 0.550 \\
\hline $\mathrm{FEV}_{1}(\mathrm{~L})$ & $1.36 \pm 0.61$ & $1.37 \pm 0.64$ & $1.29 \pm 0.46$ & 0.583 \\
\hline $\mathrm{BMI}\left(\mathrm{kg} / \mathrm{m}^{2}\right)$ & $26.8 \pm 5.8$ & $27.1 \pm 6.0$ & $25.8 \pm 4.8$ & 0.390 \\
\hline Current smoker & $28 \%$ & $28 \%$ & $26 \%$ & 0.872 \\
\hline Smoking (pack years) & $46(30,72)$ & $44(30,72)$ & $57(40,79)$ & 0.110 \\
\hline
\end{tabular}

Data are presented as percentage, mean \pm SD or median (IOR) as appropriate.

Conclusions Comorbid IHD is independently associated with a clinically significant lower exercise capacity in COPD patients. Such patients may have a higher level of fatigue before exercise and develop more dyspnoea during exercise. Such patients may be an appropriate target for further intervention such as tailored pulmonary rehabilitation.

\section{P48 SHOULD CHRONIC OBSTRUCTIVE PULMONARY DISEASE BE A CONTRA-INDICATION TO $\beta$ BLOCKER PRESCRIPTION IN PATIENTS WITH CONCOMITANT HEART FAILURE?}

doi:10.1136/thoraxjnl-2011-201054c.48

D C Lees, M Simpson, E McKay, S J Owen. Warrington and Halton General Hospitals Trust, Warrington, UK

Introduction Beta blockers (BB) are now well established in the treatment of heart failure (HF) and other cardiovascular disorders. There is much debate in the literature as to their safety in patients with concomitant chronic obstructive pulmonary disease (COPD) due to the risk of increased symptoms and decline of $\mathrm{FEV}_{1}$. As $\mathrm{BB}$ use improves morbidity and mortality in CVD are we justified in denying this benefit to patients with co-existing COPD?

Objective To ask cardiologists within our Deanery about their prescribing preferences for $\mathrm{BB}$ in patients with both HF and COPD and any adverse events they had experienced as a result of those prescriptions.

Method Four questions were sent out to 50 consultant cardiologists and 20 registrars asking $\mathrm{BB}$ of choice with adverse events experienced or reasons to avoid them.

Results 30/50 Consultants responded with $7 / 20$ registrar responses. $100 \%$ prescribed BB to patient with COPD and HF with only 6 $(16 \%)$ responders describing adverse outcomes. These included increasing shortness of breath (6/37), wheeze (6/37) and bronchospasm (1/37). The most commonly prescribed BB was bisoprolol 